\title{
The What, Why, Who, and How of Teaching Intelligence: The Leicester Approach
}

\author{
Helen Dexter, Mark Phythian and David Strachan-Morris
}

\begin{abstract}
This article uses our experience of teaching a postgraduate course in Intelligence Studies as a basis for discussion of core issues relating to contemporary intelligence education. After situating our understanding of Intelligence Studies in the context of wider debates about its nature and purpose, the article goes on to discuss key questions of how, who and what we teach when we teach 'intelligence'. It discusses the pedagogical benefits of a Distance Learning approach to teaching intelligence. It presents a picture of variegated demand arising from a dynamic and expanding professional sector and the continued appeal of studying the subject to non-professionals. It concludes that in providing 'education' rather than 'training' and taking a constructivist approach to learning as a shared journey, the 'Leicester Approach' can both improve the practice of intelligence and widen participation in key debates about intelligence.
\end{abstract}

What do we teach when we teach 'intelligence'? This is a good time to be reflecting on this question. The number of intelligence programmes delivered via higher education institutions internationally is growing and intelligence increasingly features as an element within more general Political Science, International Relations, History and other programmes. A recent Association of Former Intelligence Officers (AFIO) survey listed over 150 "Institutions Teaching About Intelligence" in the US alone. ${ }^{1}$ In addition, the number of universities in Europe offering intelligence courses is increasing. Its study is well-established in Canada and continues to develop in Australia, as well as in some countries in South America. There is also evidence of growth, albeit from a low base, in Asia. Increasingly, then, intelligence education is becoming globalised. But posing this seemingly straightforward question of what we teach when we teach 'intelligence' requires us also to consider a series of related questions: why do we teach intelligence? Who are we aiming the teaching of intelligence at? How do we teach intelligence?

\footnotetext{
${ }^{1}$ http://www.afio.com/12 academic.htm.
} 
There is no single answer to these questions. As the study of intelligence becomes increasingly global we can see a number of different approaches emerging with differing emphases, each informed by more general national political, intelligence and, of course, higher education cultures. In this regard, James Wirtz has suggested that we can identify a distinctive American approach to Intelligence Studies, characterised by: a culture of openness; a paradigm that combines social science methods and history; a focus on oversight and the impact of intelligence practice on democratic values; and a bias towards technical intelligence. ${ }^{2} \mathrm{We}$ could add to this list the sheer scale of investment in national security intelligence in the US, the number of people employed in intelligence roles by or on behalf of government, and the close interaction between intelligence professionals and intelligence academics, with academics regularly serving in government and professionals moving into universities after working in government, giving rise to the category of the 'practitioner-scholar'. The extent and regularity of this mark out the US experience of Intelligence Studies and also impact on how Intelligence Studies is delivered and understood. One consequence of this, and of the culture of higher education in the US, has been that an emphasis on the provision of what we would term 'intelligence training' via higher education institutions was an earlier and more extensive feature of intelligence courses in the US than elsewhere, although this is not to say that there has been anything approaching a uniform approach to teaching intelligence in the US. ${ }^{3}$

Stephen Coulthart and Matthew Crosston have done impressive work in mapping out what this means for the study of intelligence in the American higher education sector. ${ }^{4}$ Illustrating the point about different cultures of intelligence education, they distinguish between the provision of 'Intelligence Studies' and 'intelligence education', with the former understood as the more academic enquiry and the latter as "an umbrella term for the process of educating intelligence practitioners and scholars." 5 Their survey suggests that US intelligence curricula are based on three pillars: procedural knowledge (data management, analysis, communication, and operational skills); core knowledge (intelligence organisations and functions, historical study of intelligence, ethical and legal issues); and domain knowledge. This latter refers to "topical issues related to fields where intelligence is applied." For example, Coulthart and Crosston

\footnotetext{
${ }^{2}$ Wirtz, 'The American Approach to Intelligence Studies'.

${ }^{3}$ For a discussion that compares US and UK approaches to teaching intelligence, see Glees, 'Intelligence Studies, Universities and Security'.

${ }^{4}$ Coulthart \& Crosston, 'Terra incognita: Mapping American Intelligence Education Curriculum.'

${ }^{5}$ Ibid, p.47.
} 
discovered that nearly every intelligence programme included in their survey had a dedicated module on terrorism. The study of specific regions, particularly the Middle East, was another feature of this domain knowledge. ${ }^{6}$

The emphasis in some areas on preparation for careers in intelligence has given rise to the question of the extent to which we should consider Intelligence Studies to be a discipline or a subject area. Those involved at the training end of the Intelligence Studies spectrum are more likely to view Intelligence Studies as a discipline, as they see their role involving the preparation of 'pre-professionals' for entry into a profession, which is essentially understood to be that of the intelligence analyst. ${ }^{7}$ In this vein, leading US intelligence scholar Stephen Marrin has written of what is required to advance Intelligence Studies as an academic discipline and, reflecting on the emphasis in the US, of Intelligence Studies as "an academic complement to the practice of national security intelligence." 8 Those operating more at the 'academic' end of the spectrum are more likely to view Intelligence Studies as a multi- or inter-disciplinary endeavour, albeit with different disciplinary emphases, which cannot amount to a discipline in its own right as its methods and conceptual frameworks are drawn from existing disciplines. ${ }^{9}$ To the extent that this view has been more characteristic of the UK approach to Intelligence Studies, it also reflects something of the political and intelligence cultures prevailing in the UK in the early stages of the subject's development. In the UK, secrecy and separation, rather than the openness and connectivity of the US, marked out the academia-intelligence relationship, at least until the implementation of the recommendations arising out of the post-Iraq war Butler Review when tentative steps were taken to engage with academics working on intelligence, steps which have developed in the years since. ${ }^{10}$ Hence, in a 2004 survey of the 'Study of Intelligence in Theory and Practice', Len Scott and Peter Jackson reflected on how, "while many academics aspire to policy relevance, intelligence is one area where officialdom may remain sceptical about the value of engagement with the academy." ${ }^{11}$ It should come as no surprise, then, that as Intelligence Studies developed in the UK it did so largely in isolation

\footnotetext{
${ }^{6}$ Ibid, p.62.

${ }^{7}$ For a discussion of how far intelligence analysis has progressed towards the status of a discipline the US context, see Fisher et al, 'Is Intelligence Analysis a Discipline?'

${ }^{8}$ Marrin, 'Improving Intelligence Studies as an Academic Discipline', p.266.

${ }^{9}$ See, for example, Gill \& Phythian, 'What is Intelligence Studies?' and Richards, 'Intelligence Studies, Academia and Professionalization.'

${ }^{10}$ Butler, Review of Intelligence on Weapons of Mass Destruction. See also, Goodman, 'Studying and Teaching About Intelligence.

${ }^{11}$ Scott \& Jackson, 'The Study of Intelligence in Theory and Practice', p.153.
} 
from its subject. ${ }^{12} \mathrm{~A}$ focus on intelligence education rather than preparation for careers in intelligence was one natural consequence of this separation.

These different emphases have also given rise to different narratives about the origins of Intelligence Studies. For example, in his account Stephen Marrin locates these origins in the development of a professional literature, going back to Sherman Kent's 1955 call for the selfconscious development of a literature that would underpin professionalization ${ }^{13}$ and through to Russell G. Swenson's 2002 article on 'Meeting the Intelligence Community’s Continuing Need for an Intelligence Literature'. ${ }^{14}$ These were calls for an Intelligence Studies literature for intelligence. However, the nature of the attention given to intelligence and the vantage point of those providing it would change during the period from the mid-1970s to the mid-1980s, with consequences for understandings of the purpose of studying intelligence. From this point the literature for intelligence was joined by a growing literature about intelligence that contained an important normative dimension and represents a separate narrative of the development of Intelligence Studies.

In this version, two drivers acted roughly in parallel. The first, most associated with the United Kingdom, was the development of intelligence history. In a landmark 1984 publication, historians Christopher Andrew and David Dilks labelled this the "missing dimension", 15 thereby alerting historians to a fundamental omission and beginning the process of bringing intelligence history 'in from the cold' and into mainstream history. ${ }^{16}$ The second, most associated with the United States, was the study of intelligence as a social science project. This was stimulated by the revelations arising from the US Senate Church Committee inquiry into domestic surveillance in the US, attracting significant early work by Loch Johnson, ${ }^{17}$ and the nature and role of covert action in a democratic polity and how this should be regulated, a subject addressed via a political science framework in a 1987 book by Greg Treverton. ${ }^{18}$ The

\footnotetext{
${ }^{12}$ To repeat the point about the importance of political culture, this reflected the extent to which secrecy has been a core feature of British political culture in general, and intelligence culture in particular. See, Moran, Classified.

${ }^{13}$ Marrin, p.267; Kent, 'The Need for an Intelligence Literature.' This latter was the opening article in the first issue of Studies in Intelligence.

${ }^{14}$ Swenson, 'Meeting the Intelligence Community's Continuing Need for an Intelligence Literature'.

${ }^{15}$ Andrew \& Dilks (eds.), The Missing Dimension.

${ }^{16}$ On the historiography of intelligence history, see Moran \& Murphy (eds.), Intelligence Studies in Britain and the US.

${ }^{17}$ See, Johnson, A Season of Inquiry.

18 Treverton, Covert Action.
} 
launch of the academic journals Intelligence and National Security and the International Journal of Intelligence and Counterintelligence in the mid-1980s was, on this account, an important milestone in the development of Intelligence Studies as an academic pursuit. Prior to this time, it was generally believed that intelligence was unresearchable, and so unteachable, outside of professional intelligence contexts.

It is useful to outline the origins of Intelligence Studies as an academic pursuit in this way because doing so reminds us that, from its earliest days, its focus has been on the relationship between intelligence, the state and the broader society - or between knowledge, secrecy and power - and not simply on intelligence as a technical process or profession. We can see something of this in a review of several books on intelligence published in the US in 1985, including Loch Johnson's A Season of Inquiry, by the pioneering intelligence scholar Harry Howe Ransom. At the outset, he framed the review in terms of social science theory, reminding readers that: "No theoretical issue is more important and more difficult than the relationship of information and action: important, because knowledge is potential power and politics is about power, difficult, because analysis of the knowledge-action nexus requires understanding of cognition, perception, and communications flow in political systems." ${ }^{19}$ Earlier, Ransom had written of the challenges facing the academic study of intelligence in light of the high levels of secrecy that attached even in the relatively open system of the United States, ${ }^{20}$ but he felt that by the mid-1980s: "Patently an ample bibliography now can support widespread curricular and research attention to intelligence. Theory remains weak and tentative, and the secrecy of evidence remains a formidable problem if one wishes to go beyond historical and evaluative studies, but absence of information, ideas, and opinions is no longer an excuse to neglect intelligence as a subject for research and teaching." ${ }^{21}$ Here, Ransom was not advocating teaching simply for intelligence, but more broadly teaching about intelligence.

There were of course important national differences which meant that the study of intelligence developed at different rates and by taking different paths even in those countries where it developed earliest. For example, Peter Gill applied a version of Ransom's 1980 framework of published sources that could support the academic study of intelligence in his ground-breaking 1994 study of intelligence in the UK, which highlighted the dearth of sources and the major

\footnotetext{
${ }^{19}$ Ransom, review essay, p.985.

${ }^{20}$ Ransom, 'Being Intelligent About Secret Intelligence Agencies.'

${ }^{21}$ Ransom, review essay, pp.990-1.
} 
challenges facing social science enquiry there. ${ }^{22}$ However, significant changes were about to kick in and expand the possibilities for researching and teaching intelligence in a UK context. It has always been the case that the bounds of the possible in the study of intelligence have been largely defined by differing national levels of secrecy/openness. One measure of this has related to archival release policies and in this respect the end of the Cold War was to result in a gradual loosening of the previously vice-like approach to the official release of intelligence material into archives, creating new possibilities for studying foreign and even, as time has gone on, domestic surveillance, both of the pre-1945 and Cold War eras. Moreover, the advent and embedding of legislative oversight of intelligence in the US, Canada, Australia, the UK and elsewhere by the end of the twentieth century created a paper trail that became progressively more detailed and markedly increased the possibilities for social science research and teaching. This was a spur to increased discussion of intelligence issues and was accompanied by improved agency visibility and engagement. So too was the question of intelligence failure in relation to the era-defining terrorist attacks of September 11, $2001(9 / 11)$ and the challenging post-9/11 security environment. As a result, intelligence became a core feature of post mortem investigations by a number of commissions of inquiry of various forms. Such inquiries into intelligence failures or controversies became an established norm, generating significant volumes of oral and written evidence which were made available increasingly online - alongside detailed reports. Several years ago, Stephen Marrin made the acute point that the study of intelligence failure provides a theoretical focus or 'big question' for Intelligence Studies equivalent to that of the causes of war in International Relations. These developments meant that its study was no longer limited to those inside intelligence organisations and nor were intelligence professionals the only people with an interest in better understanding the phenomenon. ${ }^{23}$

Indeed, intelligence education can be seen as an important dimension of citizenship education, especially given the growing scale and cost to the citizen as tax-payer of national intelligence communities. In his presidential address to the 2002 American Political Science Association annual meeting, Robert Putnam made the point that an "important and underappreciated part of our professional responsibility is to engage with our fellow citizens in deliberation about their political concerns", and that academics (specifically, political scientists) had a

${ }^{22}$ Gill, Policing Politics. See chapter 1 "What Do We Know and How Do We Know It?" pp.9-47.

${ }^{23}$ Stephen Marrin first suggested this parallel in 'Intelligence Analysis Theory: Explaining and Predicting Analytic Responsibilities.' 
responsibility in contributing to "public understanding and to the vitality of democracy." $24 \mathrm{We}$ should not overlook the importance of this dimension of education for citizenship in designing intelligence courses and teaching intelligence. For example, intelligence professionals and those seeking to enter the profession have an obvious and urgent interest in better understanding the causes of intelligence failure so as to aid them in mitigating this risk, but so too have citizens if they are to be able to arrive at informed judgements about the nature and scale of investment in intelligence. Moreover, the critical thinking skills that are developed via academic exploration of these issues are transferrable skills and not only relevant in a formal intelligence context. It follows that courses in intelligence that lead to a certificate or degree outcome should be accessible to those who seek intelligence education but may prefer to use the skills and knowledge acquired in the development of careers beyond intelligence - in teaching, elsewhere in government, in journalism, the NGO sector, etc.

At the same time, however, the post-9/11 expansion of investment in intelligence, and growing awareness of the importance of applying the principles that underpin national security intelligence in a range of cognate professional roles (such as policing, customs and excise, border security, the prison service, etc.) has resulted, in the UK and elsewhere, in a growing demand of the kind that had earlier been centred on the US, especially leading to qualifications that would serve to fill the gap created by the absence of internationally-recognised professional qualifications of the kind found in teaching, medicine, law, and so on. Clearly, intelligence education has to be relevant and of use to those pursuing or engaged in these professional roles who seek to deepen their understanding and so assist in career development. To what extent does this mean that designers of postgraduate courses face a challenge of squaring the circle between those who would view intelligence education primarily as a means of supporting national security and those who would also emphasise the broader need to develop Intelligence Studies as an academic subject that draws on a range of social science and historical approaches?

Our view is that the broad education provided by an inter-disciplinary Intelligence Studies framework, which can be seen as being based on what Stephen Coulthart and Matthew Crosston characterised as the 'core knowledge' pillar at the expense of a detailed focus on the 'procedural' and 'domain' knowledge pillars (which would necessarily involve diluting the depth of coverage of 'core knowledge'), provides the most appropriate way to meet these

${ }^{24}$ Putnam, 'APSA Presidential Address', p. 249. 
requirements at postgraduate level. ${ }^{25}$ For example, it is not at all clear that those who seek careers in national security intelligence are best served by taking intelligence courses that focus narrowly on analytic techniques. In a December 2016 opinion piece in the Washington Post, former CIA historian turned Intelligence Studies academic Nicholas Dujmovic wrote of how "the intelligence agencies themselves prefer to teach the "how to" of intelligence analysis to new employees", and warned against undergraduate intelligence programmes at US universities focusing on technical aspects of intelligence to the extent that they, "supplant the study of those disciplines that help intelligence officers understand the world."26

He went on to argue that:

These intelligence degree programs are popular, they are well staffed, and they are expensive, but for all that, they fail to clearly deliver a demonstrable advantage while keeping the student from majoring in something that might actually get him or her hired and that would offer the best chance at success in an intelligence career. ${ }^{27}$

We agree with his warning, but at the same time think that a broad understanding of the world, including the lessons of the past, ${ }^{28}$ and the place of intelligence within it is precisely what Intelligence Studies can and should provide. We also emphasise the acquisition of critical skills alongside knowledge and understanding. In what follows we draw on our experience of teaching intelligence at the University of Leicester, rooted in the idea of 'Intelligence Studies' as a definable subject area that draws on different disciplinary inputs, one that reflects our belief that postgraduate courses in intelligence should provide more than enhanced skills training. They should enable those taking them to not only become more reflexive about their profession, but also to engage in the key debates and be able to feed learning back into the academic study of intelligence. Intelligence managers, for example, especially those who aspire to senior roles within the profession, whether inside or outside government, need to be more than simply technical experts in their respective and narrow fields. They also need to develop a wider

\footnotetext{
${ }^{25}$ Clearly, it is possible to provide bespoke CPD courses that focus on specific elements of 'procedural' or 'domain' knowledge outside of the MA framework or that address other specific professional requirements.

${ }^{26}$ Dujmovic, 'Colleges Must Be Intelligent About Intelligence Studies.'

${ }^{27}$ Ibid.

${ }^{28}$ See, for example, Andrew, 'Intelligence Analysis Needs to Look Backwards Before Looking Forward.'
} 
understanding of the role of intelligence within society and the key social sciences debates that surround it and are intended to facilitate arrival at efficacious outcomes.

\section{Pedagogy and the Benefits of the Distance Learning Approach}

Our MA Intelligence and Security course is one of a suite of MA courses in the broad area of security that is delivered via a Distance Learning approach. The theory that informs our pedagogical approach to Distance Learning is that of social constructivism. A social constructivist approach to education views teachers and students as partners engaged in a joint enterprise of knowledge production. Students are viewed as active participants in knowledge construction not as passive recipients. ${ }^{29}$ This theory is translated into our Distance Learning and teaching through three key strategies; a social approach to learning, reflective practice, and problem-solving though the use of case studies. We start from the premise, then, that learning is an active, social process. Rather than imparting knowledge to students we aim to provide an online environment where students can develop knowledge and understanding for themselves.

Our module design is informed in large part by Salmon's five stage model of collaborative online learning, ${ }^{30}$ which is itself premised on a social constructivist approach to education. It does not assume that digital literacy is something that must be acquired before undertaking online studies or that these skills be learnt separately. Rather, it assumes that people learn best through doing, therefore students will learn to use digital tools as they learn through digital tools. ${ }^{31}$ The model aims to encourage individual confidence with key learning technologies, build a sense of community and peer support, facilitate collaborative and meaningful interaction and support independent learning. Stage 1 (Access and Motivation) ensures students have easy access to the learning platform and allows them to explore and become comfortable with their learning environment. As social learning requires a sense of group identity and the identification of shared aims Stage 2 (Online Socialisation) aims to build trust and understanding between participants. Stage 3 (Information Exchange) encourages the sharing of information between participants in order to highlight to students the value of their own

\footnotetext{
${ }^{29}$ McCombs \& Whisler, The Learner-Centered Classroom and School; Ramsden, Learning to Teach in Higher Education; Jones \& Brader-Araje, 'The Impact of Constructivism on Education.'

${ }^{30}$ Salmon, E-Moderating, pp.32-53.

31 ibid, p.31.
} 
participation and that of their peers. Stage 4 (Knowledge Construction) develops information exchange into genuine dialogue. Participants engage in productive conversation, consider different views, make sense of course materials together, reflect on their own understanding and negotiate meaning through genuine dialogue. Finally, Stage 5 (Development) sees participants take responsibility for their own learning though independent projects.

Distance Learning is taught entirely through our Virtual Learning Environment, Blackboard. At the beginning of each 10-week module (which are taken sequentially rather than in parallel) students are provided with a reading list divided into weekly topics that are accompanied by questions and case study exercises designed to stimulate critical engagement with that week's literature. Each week students will use the online forums to discuss their reading, ask questions, share ideas and develop debates. Each forum is moderated by an academic who is responsible for ensuring appropriate pacing and development and that all key issues are adequately explored before students progress to the next topic. Alongside weekly reading and discussions students are also expected to complete six 'e-tivities' (the term we use for online activities) per module. Drawing on Salmon's model our e-tivities are designed to develop key skills and build a sense of online community. E-tivities see students share information with each other and provide peer support and review and take the form of a combination of formative and summative assessments designed to complement and support the learning objectives for each particular module. Following the initial module, the e-tivities on the modules that follow are also designed to encourage students to reflect on their previous learning experiences. Written feedback is provided at the end of each e-tivity.

Learning is a collaborative process, and this is why the online forums accessed through Blackboard are central to our teaching. Whilst there is an increasing expectation that online teaching will involve the use of video lectures, research suggests that on average a student will watch a video for six minutes before their attention wanes. ${ }^{32}$ In a class room environment student attention during a lecture stretches only to around ten to fifteen minutes, ${ }^{33}$ which perhaps helps explain why the notion of active learning has grown in popularity over the last few years. Following a review of the literature, Michael Prince concludes that active learning is best summarised as "any instructional activity that engages students in the learning

\footnotetext{
${ }^{32}$ Guo, 'Optimal Video Length for Student Engagement.'

${ }^{33}$ Richardson, 'Students have 10 minute attention span'; Bunce et al, 'How long Can Students Pay Attention in Class?'
} 
process." ${ }^{34}$ Methods might include class debate and discussion, group work, role play, simulations, game playing and problem solving. It is an approach that sees students actively work to acquire knowledge for themselves rather than passively listening to an 'expert' as they would in a traditional lecture environment. There is growing consensus that active learning improves both assessment scores and student retention. ${ }^{35}$

Student interaction, then, is key to active learning. Not all forms of interaction however will result in learning. Or perhaps to be more precise, not all forms of interaction will direct students towards the intended learning outcomes. As much as we want to see students chatting away on the forum, skilled curriculum design and online moderation is required to facilitate learning. As Woo and Reeves argue, "[m]eaningful interaction is not just sharing personal opinions. Instead, the interaction must stimulate the learners' intellectual curiosity, engage them in productive instructional activities, and directly influence their learning." 36 Hence the importance of case studies in providing an engaging narrative with which to structure this social learning. Case studies provide an important mechanism to focus dialogue. Students can draw on their shared experiences and different views and direct them towards the shared task of critically analysing the case study material. Problem-based learning such as this ensures that students play an active role in the learning process rather than merely being passive recipients.

The C. Roland Christensen Centre for Teaching and Learning at the Harvard Business School (whose founder is considered the father of the case study method) sums up a case study approach as "the art of asking the right question, of the right student, at the right time - and in the right way." ${ }^{37}$ The role of the teacher is key in developing and presenting materials in a way that provides meaningful interaction. In the age of the internet information is freely available and one does not need to enrol in an expensive degree programme in order to access useful information. In this context, the value of the academic approach we take to intelligence education lies in the social interaction and the critical role of the teacher in promoting, fostering and directing critical reflexivity. Whilst at the start of the process the problem-solving approach

\footnotetext{
${ }^{34}$ Prince, 'Does Active Learning Work?'

${ }^{35}$ Freeman et al, 'Active learning Increases Student Performance in Science, Engineering and Mathematics.'

${ }^{36}$ Woo \& Reeves, 'Meaningful Interaction in Web-Based Learning', p.16.

${ }^{37} \mathrm{C}$ Roland Christensen Centre for Teaching and Learning at the Harvard Business School, (2008), 'Questions for Class Discussion'.
} 
to learning might involve asking the 'right question, of the right student at the right time', before long it should be the students themselves who determine what the right questions are.

Social constructivism also stresses that learning should be authentic if it is to promote higher order thinking. That is to say, content should relate to the lived experiences and social reality of the student. Our case studies are derived through partnership with the student body and alumni. This ensures that the content of our modules is relevant, and that it relates directly to the experiences of the community of practice. Students are co-creators of their own and future curricula, placing our approach to Distance Learning squarely within the UK Higher Education Academy's (HEA) Flexible Learning Framework. ${ }^{38}$

Hosting discussions online brings its own set of challenges. For some the process of translating their thoughts into writing can be more daunting and intimidating than simply discussing a topic face-to-face. Something said out loud can be quickly forgotten, but text added to a forum remains. This can, of course, provide a useful resource for all course members - a repository of ideas - but this resource brings with it the pressure to say the 'right things' - something that will impress your peers and your tutor, your best work. This pressure to impress can sometimes lead to overly long contributions that stifle the debate either by appearing to be the definitive answer, or because others don't have the time to add a similarly long response. The asynchronous nature of our modules also means that once a student has posted, they may have to wait a day or more for a response. This means that it can be difficult to get into the flow of a debate. We use a number of mechanisms to try to mitigate these challenges. The most important is the development of a sense of community amongst the students and to remind students that forums should be a relaxed and supportive environment and are not a competitive realm.

Online forums also bring a number of benefits to the learning experience, which is why they are increasingly used to complement campus teaching. For those individuals who are uncomfortable with speaking in public, forums provide an opportunity to have their voices heard. They also provide a space to think, time to digest and reflect on an article or a post by someone else. Any pressure to come up with a spontaneous response is removed. This space can allow for deeper thinking and a more meaningful exchange of views. Forums can also help to overcome the gendered nature of the classroom. Female students studying on campus report that seminars are often dominated by men ${ }^{39}$ and research supports this. Whilst certain voices

\footnotetext{
${ }^{38}$ Higher Education Academy, (2015), 'Flexible Learning in Higher Education.'

${ }^{39}$ Roberts, 'University politics seminars are a breeding ground for chauvinism.'
} 
can still dominate even in an online forum the physicality of a heated debate is removed. Anyone can post in their own time. The role of moderator is important here too. As well as moderating the forum as posts are made, the academic overseeing the development of the online discussion forum will provide a summary of the weekly discussion. Here posts that were perhaps overlooked by other students or arguments that were not properly acknowledged can be reprieved and reintroduced for further consideration.

\section{What Do We Teach When We Teach Intelligence Studies?}

These are the pedagogic underpinnings and benefits of our Distance Learning approach. How, then, do we apply this method in the specific context of Intelligence Studies? In designing the MA Intelligence and Security course, we have aimed to provide an open Intelligence Studies education accessible to all, but one that meets Continuing Professional Development requirements for intelligence managers and aspiring intelligence managers and so addresses the professionalization of intelligence as an activity. The benefits of the broader Intelligence Studies approach at middle management level are clear. For example, recent allegations of politicisation and distortion of intelligence at the US Central Command (CENTCOM) were found to have resulted from a poor management climate and a perception that intelligence was being distorted because of a lack of understanding of the review process, as well as a lack of understanding of the different perspectives of the intelligence agencies involved. The final report of the Department of Defense Inspector General found that intelligence managers within CENTCOM had applied a fairly rigid review and editing process to reports but had not put their feedback in a wider context of how this reporting was being used at higher levels and why certain changes were required. ${ }^{40}$ Although the report does not make any recommendations about improved training or education and there is no indication of what level of intelligence education the main protagonists in the affair had received, the report does refer to an internal initiative within the CENTCOM intelligence branch launched in February 2015 that included enhanced information about, and access to, internal and external training opportunities. ${ }^{41}$

\footnotetext{
${ }^{40}$ U. S. Department of Defense Office of Inspector General, Unclassified Report of Investigation of Allegations Relating to US CENTCOM Intelligence Products, pp.137-8 \& $140-3$.

${ }^{41}$ Ibid, p133.
} 
As noted above, the course takes a case study-based approach, one aim of which is that graduates can not only apply a wider understanding of intelligence and its place in society but can also contribute to future courses by providing case studies that they can guide students through with a combination of practical experience and theoretical understanding, within the wider Intelligence Studies framework provided by the academic staff. We follow Gill and Phythian's categorisation of the four main areas of contemporary Intelligence Studies focus (also recognisable in the 'core knowledge' pillar identified by Coulthart and Crosston) - the research/historical, the definitional/methodological, the organizational/functional, and governance/policy ${ }^{42}$ - and address each of these via the course. In a similar vein, Martin Rudner's 2009 survey of Intelligence Studies resulted in a prototypal postgraduate course that concentrated on three of these areas: research/historical; organizational/functional; and governance/policy. ${ }^{43}$ None of the modules Rudner listed, however, seemed to examine the definitional/methodological area of study. However, this is a crucial foundation which seeks to provide a "more extensive and critical understanding of what [intelligence] is", based on intelligence being "a pre-eminently social and political phenomenon, not simply a technical discipline." ${ }^{44}$ In particular, it poses fundamental questions of whether we should view intelligence as simply an information or knowledge process, or (to return to Harry Howe Ransom's point) whether it is also a power process. ${ }^{45}$ This, then, is a key aspect of the study of intelligence and one that helps distinguish an Intelligence Studies course from one with a more narrow focus on intelligence training.

Hence, the first of the four taught modules that, together with the 15,000-word dissertation, comprise the course - Intelligence: Key Concepts and Debates - is designed to introduce the key theoretical concepts and debates in the study of intelligence. It explicitly poses the question of 'what is intelligence?' - one that is simply stated but by no means easy to satisfactorily answer. From there it goes on to ask how social science concepts can contribute to critical thinking about the application and utility of intelligence? How useful is the intelligence cycle model, and what are its limitations? What are the limits of intelligence? Each of these raise

\footnotetext{
${ }^{42}$ Gill \& Phythian, 'What Is Intelligence Studies?' p 8. This is based on an updating of the categorisation proposed in Wesley Wark in the early 1990s in the early stages of the development of Intelligence Studies. See, Wark, 'Introduction: The Study of Espionage: Past, Present, Future?'

${ }^{43}$ Rudner, 'Intelligence Studies in Higher Education', pp.121-122.

${ }^{44}$ Gill \& Phythian, pp.7, 8.

${ }^{45}$ Ibid, pp.9-10; Gill \& Phythian, Intelligence in an Insecure World, Chs. 1-2.
} 
subsidiary questions that are of significance for the professional, aspiring professional and interested or concerned citizen alike. This provides a basis for the second module, Intelligence Techniques and Tradecraft, which allows students to develop a critical understanding of relative strengths and weaknesses of different collection and analytical techniques. While learning about critical thinking, structured analytical techniques, and forecasting, the students also analyse the analyst-policymaker interface and the communication of assessments and analysis to policymakers - a key issue for aspiring intelligence managers, but a set of considerations and skills relevant to most organisational contexts.

This, in turn, forms the basis for the third module, Intelligence Failure. This module adopts a case study approach, drawing cases from national security and policing intelligence, to reflect on the nature and meaning of 'failure' in intelligence contexts, examine why failure occurs, and how its risk can be mitigated. The important role of a case studies approach to teaching intelligence has long been recognised, reflecting the extent to which the study of intelligence has an inevitable post mortem quality - in essence, it is essential to look back to understand the most effective approaches to a pursuit that involves looking into the future. ${ }^{46}$ A number of the case studies used by us are those that are generally regarded as being of particular importance in illuminating aspects of the debate about the causes and nature of intelligence 'failure' and for which official inquiries have given rise to a particularly rich paper trail, such as the 9/11 attacks and the Iraqi weapons of mass destruction debacle. However, some of the additional cases that we use have been suggested by law enforcement intelligence officers to enhance understanding of how intelligence works at the sub-state level. These include the Whitemoor Prison Escape and the Soham Murders as case studies in intelligence failure. The final module focuses on Intelligence Ethics to facilitate discussion of the ethical dimension of intelligence practice, using a case study approach that once again draws cases from national security and policing intelligence. Themes in intelligence ethics are similarly explored via a case studies approach - for example, examination of Project Champion, a surveillance initiative in Birmingham, and in relation to the activities of officers of the undercover Special Demonstration Squad of the Metropolitan Police.

\footnotetext{
${ }^{46}$ For example, Handel, 'The Study of Intelligence'; Phythian, 'Intelligence Theory and Theories of International Relations; Wirtz, 'The Art of the Intelligence Autopsy'; and Caddell, \& Caddell, 'Historical Case Studies in Intelligence Education.'
} 
There is no reason why these modules cannot be taken for different purposes but with equal benefit by a range of practitioners with different backgrounds (professional and geographical) as well as non-practitioners. All can benefit from the insights and perspectives of others in a collaborative, social, learning process. For example, intelligence ethics is occupying an increasingly important place in professional practice and understanding of principles and debates is clearly important in these contexts. Yet it is also an issue that has generated significant public concern in the post-9/11 period and its inclusion here also recognises Robert Putnam's argument that, "our discipline, more than any other social science, gives a place of honor to explicit, reasoned debate about normative issues" which means that, "we have an unusual potential to frame issues that inevitably straddle the fact-value boundary." 47

Principles derived from the study of national security intelligence form a basis for the study of intelligence in other contexts, such as policing, but there are exceptions and variations. Engaging with practitioners in law enforcement in the design and delivery of the course has helped us draw these out. For example, law enforcement and military practitioners can have a very different perspective on the debate over the validity of the intelligence cycle. Moving in the other direction, our students from law enforcement have found great value in applying James Sheptycki's critiques of law enforcement intelligence as a model to examine state level intelligence failure in the 9/11 attacks and in relation to intelligence on WMD in Iraq. ${ }^{48}$ Having these different perspectives becomes especially useful when investigating the interface between state and sub-state level intelligence, for example when looking at the 7 July 2005 terrorist attacks in London as a case study, as a result of which the Security Service (MI5) and the police were both criticised for intelligence failures.

By providing postgraduate education in Intelligence Studies through the medium of online Distance Learning the distribution to, and engagement of, practitioners increases dramatically. The asynchronous nature of Distance Learning and the fact that students are not required to attend a physical location allows practitioners in the field or working unsociable hours arguably those who need this type of education most - to fit the course into their schedules. The open nature of the course (in that there are no nationality or security clearance restrictions) extends the reach of Intelligence Studies beyond the traditional 'Five Eyes' countries, bringing in perspectives from Africa, the Far East, and Central Asia. This allows countries with no

\footnotetext{
${ }^{47}$ Putnam, p.251.

${ }^{48}$ Sheptycki, 'Organisational Pathologies in Police Intelligence Systems.'
} 
current means of providing advanced intelligence education themselves can access this education at a reasonable cost, while also helping to develop Intelligence Studies as an academic field in those countries and to promote normative values. Approximately half of our students are from outside the UK, many from outside the Anglosphere and Five Eyes countries. The list of countries currently represented on the MA in Intelligence and Security at Leicester includes Canada, Finland, Nigeria, Kenya, Somalia, India, Greece, Turkey, the Netherlands, and Malta, with at least two students from each of these nations. This makes the constructivist concept of education being a joint enterprise an even more important element of the course. Not only does the use of Distance Learning facilitate access to intelligence education for those who would not otherwise be able to participate, it also brings in much-needed perspectives from nations who are often 'acted on' in intelligence but are rarely seen as actors in their own right. For example, a recent discussion in the course forum included contributions from the Finnish students from their perspective as a nation caught in the intelligence war between the USA and the Soviet Union during the Cold War. Nigeria, Kenya, and Somalia are all heavily engaged in counter-terrorist campaigns and provide enormous potential for useful case studies that we hope will demonstrate how the students have applied their intelligence education and promote active participation in key debates on intelligence from outside the Anglosphere/Five Eyes 'bubble'.

Moving beyond this geographical range, the students taking the course at Leicester can be divided into four broad groups ${ }^{49}$. The first, and by far the largest, are intelligence practitioners from law enforcement, the military and, to a lesser extent, government. These practitioners often have several years' professional experience in the field of intelligence and have undergone extensive training in their particular specialisations; the majority being either analysts or field operators of some sort (either HUMINT operators or surveillance operators). While they are looking to broaden their professional knowledge, they are also looking for the kind of deeper understanding of intelligence and the ideas underpinning it that will be required in senior management or policymaking roles.

The second group consists of professionals working in the security field who are not necessarily in intelligence roles. They include military officers in staff jobs and commercial security managers who believe intelligence is an important element of security and want to improve

\footnotetext{
${ }^{49}$ What follows is based upon applications for admission, which include personal statements explaining why the applicant wants to take this particular course.
} 
their understanding of it. This latter sub-group are increasingly finding that a postgraduate qualification is becoming a requirement for progression into senior management roles.

The third group, smaller than the first two, comprises graduates looking for their first step into a career; as with the security professionals they are finding that 'qualification creep' has meant that a postgraduate qualification is now as important as a degree once was. ${ }^{50}$ While some are seeking entrance into intelligence, others are looking for entry into cognate fields such as commercial political risk, while the remainder have no clear idea of their intended career field but find the subject matter in the MA course interesting.

There is a fourth group of students which, although small, is still essential to Intelligence Studies. They are not necessarily looking for professional intelligence or security careers but are keen to learn about intelligence. Some are aspiring academics who intend to use the course as a springboard to $\mathrm{PhD}$ research in the field of intelligence; the next generation of Intelligence Studies scholars. The rest are the interested or concerned citizens who want to know more about how intelligence is used in their societies and what their taxes are being spent on. By catering to this group in an environment in which they get an education in intelligence alongside practioners, Intelligence Studies fulfils the obligation outlined by Putnam and also satisfies a wider educational purpose in providing transferable skills to those who may go on to work in other areas.

The initial findings of a longitudinal study of our MA students supports this approach to teaching intelligence across these groups. While some respondents have said that a certain practical element might be useful, particularly with regard to analytical tools, most agree that training is best left to the organisation that employs them and that what they are looking for from the MA course is a wider intelligence education. ${ }^{51}$ This reflects the fact that existing professionals will already have had extensive training in their fields, so we should not seek to replicate this. Those looking to enter the intelligence field will get this training if they are successful; it is also unlikely that an open-entry unclassified course can provide the same level of training. One student, a former officer in the British Army Intelligence Corps who is now a director within a multinational defence contractor, wrote in response to a question about the

\footnotetext{
${ }^{50}$ Lindley \& Marchin, The Postgraduate Premium: Revisiting Trends in Social Mobility and Educational Inequalities in Britain and America.

${ }^{51}$ Survey of 64 students on the University of Leicester MA DL Intelligence and Security course with questionnaires sent to all students between December 2016 and March 2017.
} 
'education vs. training' debate: "The broad education in my view is the important context of the Intelligence domain rather than the specific detail of the operating environment in which an individual sits. Any Army Intelligence Corps analyst works in a very different environment to a Police analyst, but the course can provide either of them with the knowledge needed to be able to move around within the domain". He went on to say that: "The discipline is much broader and more complex than I had originally thought. There is a myriad of technical, moral, ethical, geopolitical, operational, regulatory, organisational etc. issues at play which makes it so interesting... It has provided me with a more rounded knowledge of Intelligence which enables me to contribute more to discussions with internal and external stakeholders". ${ }^{52}$ This last point speaks to the issues found within CENTCOM that we referred to earlier; arguably a 'more rounded knowledge of intelligence' might have provided an environment in which its senior management could have put their processes into the wider context of CENTCOM's place in the intelligence community and had sufficient awareness of politicisation to have been able to avoid the perception among their 'internal stakeholders' that this was happening to their reporting.

This approach to Intelligence Studies, then, is premised on the importance of a broad academic intelligence education that can support the professionalization of intelligence as a career field as that field develops rapidly in several directions. It is particularly important, for example, in law enforcement and in the growing commercial intelligence sector. Within the military and the government intelligence is a clearly-defined branch, with specialised training, an organisational structure, and a career development process. In law enforcement intelligence is a less clearly-defined career field and is considered very much a subordinate activity. In the UK it is mainly the realm of civilian employees with police officers posted in for a few years at a time (the exception being Special Branch, which concentrates on political subversion and terrorism). In the US it is only recently that the FBI has created a career field for agents in the Directorate of Intelligence, but the 'cultural pathologies' identified by Amy Zegart still exist to a certain extent in British law enforcement. ${ }^{53}$ This is beginning to change and there is now an Intelligence Professionalisation Programme under way, led by the National College of Policing. In the commercial world of intelligence, however, the idea of an intelligence professional is even vaguer. A typical department can consist of journalists, former intelligence

\footnotetext{
${ }^{52}$ David Strachan-Morris, Survey of MA DL Intelligence and Security Students, December 2016.

${ }^{53}$ Zegart, '9/11 and the FBI: The Organisational Roots of Failure.'
} 
personnel, political scientists, economists, and country or regional experts. The increase in nontraditional and non-state-based threats has increased the need in the commercial world for the same type of intelligence products that were once the preserve of governments. ${ }^{54}$ This has widened the field of intelligence practitioners considerably.

This is where intelligence education and possession of a postgraduate qualification in Intelligence Studies can provide a framework for the professionalisation of the intelligence field across government and commercial organisations. Medical and law practitioners come from professions with a vast body of practical and academic learning to underpin what they do and have a professional body as a prerequisite for practice. The relationship between academia and practice in the context of intelligence is very similar to that in the legal profession. While aspiring lawyers (in the UK) may learn a great deal about the law while studying for their law degree they can only become solicitors or barristers after professional training within a law firm or barristers' chambers. One can only become an intelligence practitioner through employment, which entails specific professional training to a greater or lesser extent depending on where one is employed, regardless of whether one already has an undergraduate or postgraduate degree in intelligence. The relationship between intelligence and Intelligence Studies can arguably be compared with that between the law and jurisprudence. Study of the law can provide one with an understanding of legislation and how to prosecute a case, but it is the study of jurisprudence that provides a wider understanding of the philosophy and social theory that underpins and surrounds the practice of law. A combination of law and jurisprudence provides the basis upon which the practice of law has become a profession. Possession of a postgraduate qualification in Intelligence Studies can provide support for an application for membership of a professional institute such as The Security Institute in the UK. ${ }^{55}$ There is no professional body solely for intelligence professionals but there is a case to be made that one should exist.

\section{Summary}

This article has discussed the philosophy underpinning our approach to teaching Intelligence Studies. It noted differences in national approaches to understandings of Intelligence Studies. The more open and connected US approach, with its large intelligence bureaucracy and

\footnotetext{
${ }^{54}$ Donald, 'Private Security and Intelligence.'

${ }^{55}$ The Security Institute, https://www.securityinstitute.org/Join/professional membership academic pathway, accessed 13 March 2017.
} 
resultant employment possibilities, has long seen higher education providers view their role, at least in part, as preparing people for careers in intelligence. In the UK high levels of secrecy and separation (perhaps even mutual suspicion) between academia and intelligence helped shape a different approach, and here Intelligence Studies developed with different emphases. The academic framework for the subject forged in these early years still forms the basis for teaching Intelligence Studies in an era of greater connectivity as demand has shifted to include government, the police, cognate professions, and private sector intelligence professionals, alongside those with an interest in intelligence education who do not seek to enter a career in intelligence, but one where they can still use intelligence education (such as teaching, journalism, the NGO sector, etc.). Hence, the student body is diverse and the course needs to be able to meet the career development goals of all those engaged on the course.

Within this, it is important that we deliver Intelligence Studies in such a way that practitioners play an active role in their own education, one that enables the discipline to move beyond support to national security and facilitates the professionalization of intelligence by providing a body of knowledge that practitioners can engage with to enhance their own understanding and improve their performance, and that of the agency they work for. The education they receive as postgraduate students adds value to the training they have had within their organisation by giving them the academic and intellectual tools to critically analyse the processes and methods they use and to be able to place them into the wider context of the intelligence community and society in general. Thus we are able to square the circle of training versus education by educating practitioner-scholars who have a deeper understanding of the professional training they have received and the context within which they use it. As a mode of delivery, Distance Learning provides opportunities to extend Intelligence Studies beyond the Anglosphere and Five Eyes countries, enhancing the development of intelligence practitioners in all parts of the world and, in turn, enabling them to bring new perspectives to the field of Intelligence Studies.

\section{Notes on Contributors}

Dr Helen Dexter is Associate Professor of International Politics at the University of Leicester and Director of Distance Learning for the School of History, Politics and International Relations. Her research addresses the relationship between ethics and political violence with a current focus on the place (or absence) of pacifism in International Relations. When not 
working Helen practices riot control and conflict resolution techniques on her two young children.

Professor Mark Phythian is Professor of Politics in the Department of Politics and International Relations at the University of Leicester. His research interests are in the areas of intelligence and national security. He is the author or editor/co-editor of some dozen books on intelligence and security topics, including Intelligence in an Insecure World (with Peter Gill, $2^{\text {nd }}$ ed. Polity Press, 2012) and (as editor) Understanding the Intelligence Cycle (Routledge, 2013), as well as numerous journal articles and book chapters. He is co-editor of Intelligence and National Security and a Fellow of the Academy of Social Sciences.

Dr. David Strachan-Morris is a Lecturer in Intelligence and Security at the University of Leicester, where he runs the MA Intelligence and Security programme as well as being Deputy Director of Distance Learning for the School of History, Politics and International Relations. Before embarking on an academic career he served in the Intelligence Corps in the British Army and worked in intelligence management roles in the private security industry in Iraq. His current research projects focus on intelligence education and strategic intelligence.

\section{References}

Andrew, Christopher. "Intelligence Analysis Needs to Look Backwards Before Looking Forward.” Policy Paper, History and Policy, June 2004, available at:

http://www.historyandpolicy.org/policy-papers/papers/intelligence-analysis-needs-to-lookbackwards-before-looking-forward.

Andrew, Christopher and David Dilks (eds.). The Missing Dimension: Governments and Intelligence Communities in the Twentieth Century. London: Macmillan, 1984.

Bunce, Diane M., Elizabeth A. Flens and Kelly Y.Neiles. "How Long Can Students Pay Attention in Class? A Study of Student Attention Decline Using Clickers." Journal of Chemical Education 87, no. 12: 1438-1443.

Butler, Lord Robin. Review of Intelligence on Weapons of Mass Destruction: Report of a Committee of Privy Counsellors. HC 898. London: TSO, 2004.

C Roland Christensen Centre for Teaching and Learning at the Harvard Business School. "Questions for Class Discussion." (2008). Available at:

http://www.hbs.edu/teaching/Documents/Questions for_Class_Discussions rev.pdf.

Caddell, Joseph Jr. \& Joseph Caddell Sr. "Historical Case Studies in Intelligence Education: Best Practices, Avoidable Pitfalls." Intelligence and National Security 32, no. 7 (2017): xxxxxx.

Coulthart, Stephen and Matthew Crosston. "Terra incognita: Mapping American Intelligence Education Curriculum.” Journal of Strategic Security 8 No.3 (2015): 46-68; available at: http://scholarcommons.usf.edu/cgi/viewcontent.cgi? article=1459\&context=jss. 
Donald, Dominick. "Private Security and Intelligence." in Andrew Alexandra et al (eds.), Private Military and Security Companies: Ethics, Policies and Civil-Military Relations. Abingdon: Routledge, 2008.

Dujmovic, Nicholas. "Colleges Must Be Intelligent About Intelligence Studies." Washington Post, 30 December 2016; https:/www.washingtonpost.com/news/gradepoint/wp/2016/12/30/colleges-must-be-intelligent-about-intelligencestudies/?utm term=.71a3d1abc669.

Fisher, Rebecca, Rob Johnston and Peter Clement. "Is Intelligence Analysis a Discipline?" In Roger Z. George and James B. Bruce (eds.), Analyzing Intelligence: National Security Practitioners' Perspectives. $2^{\text {nd }}$ ed. Washington, DC: Georgetown University Press, 2014: 57-77.

Freeman, Scott et al. "Active Learning Increases Student Performance in Science, Engineering and Mathematics." PNAS 111, no. 23 (2014): 8410-8415.

Gill, Peter. Policing Politics: Security Intelligence and the Liberal Democratic State. London: Frank Cass, 1994.

Gill, Peter and Mark Phythian. Intelligence in an Insecure World. $2^{\text {nd }}$ ed. Cambridge: Polity Press, 2012.

Gill, Peter and Mark Phythian. "What is Intelligence Studies?" The International Journal of Intelligence, Security, and Public Affairs 18, no. 1 (2016): 5-19.

Glees, Anthony. "Intelligence Studies, Universities and Security." British Journal of Educational Studies 63, no. 3 (2015): 281-310.

Goodman, Michael S. "Studying and Teaching About Intelligence: The Approach in the United Kingdom.” Studies in Intelligence 50, no. 2 (2006): 57-65, available at: https://www.cia.gov/library/center-for-the-study-of-intelligence/csi-publications/csistudies/studies/vol50no2/html files/Studying Teaching 6.htm\# ftnref24.

Guo, Philip. “Optimal Video Length for Student Engagement.” edX 13 November 2013; available at http://blog.edx.org/optimal-video-length-student-engagement.

Handel, Michael I. “The Study of Intelligence.” Orbis 26, no. 4 (1983): 817-821.

Higher Education Academy. "Flexible Learning in Higher Education." (2015), available at: https://www.heacademy.ac.uk/system/files/downloads/higher_education_academy_flexible learning framework - 210416.pdf.

Johnson, Loch K. A Season of Inquiry: The Senate Intelligence Investigation. Lexington, KT: University of Kentucky Press, 1985.

Jones, Gail M. and Laura Brader-Araje. "The Impact of Constructivism on Education: Language, Discourse, and Meaning." American Communication Journal 5, issue 3 (2002), available at: http://ac-journal.org/journal/vol5/iss3/special/jones.pdf. 
Kent, Sherman. "The Need for an Intelligence Literature." Studies in Intelligence, Spring 1955, pp.1-11; https://www.cia.gov/library/center-for-the-study-of-intelligence/csipublications/books-and-monographs/sherman-kent-and-the-board-of-national-estimatescollected-essays/2need.html.

Lindley, Joanne and Stephen Marchin. The Postgraduate Premium: Revisiting Trends in Social Mobility and Educational Inequalities in Britain and America. London: The Sutton Trust, February 2013.

Marrin, Stephen. "Intelligence Analysis Theory: Explaining and Predicting Analytic Responsibilities." Intelligence and National Security 22, no. 6 (2007): 821-846.

Marrin, Stephen. "Improving Intelligence Studies as an Academic Discipline." Intelligence and National Security 31, no.2 (2016): 266-279

McCombs, Barbara L. and Jo Sue Whisler. The Learner-Centered Classroom and School: Strategies for Increasing Student Motivation and Achievement. San Francisco: Jossey-Bass Inc, 1997. Available at: http://www.indiana.edu/ syschang/decatur/2007_fall/documents/22 mccombs ch1.pdf.

Moran, Christopher. Classified: Secrecy and the State in Modern Britain. Cambridge: Cambridge University Press, 2012.

Moran. Christopher R. and Christopher J. Murphy (eds.). Intelligence Studies in Britain and the US: Historiography since 1945. Edinburgh: Edinburgh University Press, 2013.

Phythian, Mark. "Intelligence Theory and Theories of International Relations: Shared World or Separate Worlds?” In Peter Gill, Stephen Marrin \& Mark Phythian (eds.), Intelligence Theory: Key Questions and Debates. Abingdon: Routledge, 2009: 54-72

Prince, Michael. "Does Active Learning Work? A Review of the Research." Journal of Engineering Education 93, no. 3: 223-231.

Putnam, Robert D. “APSA Presidential Address: The Public Role of Political Science." Perspectives on Politics 1, no. 2 (2003): 249-255

Ramsden, Paul. Learning to Teach in Higher Education. 2nd edn. London: Routledge, 2003.

Ransom, Harry Howe. "Being Intelligent About Secret Intelligence Agencies." American Political Science Review 74, no. 1 (1980): 141-148.

Ransom, Harry Howe. Review essay. American Political Science Review 80, no. 3 (1986): 985-891.

Richards, Julian: "Intelligence Studies, Academia and Professionalization." The International Journal of Intelligence, Security, and Public Affairs 18, no. 1 (2016): 20-33.

Richardson, Hannah. "Students have 10 minute attention span." BBC News 12 January 2010, available at http://news.bbc.co.uk/1/hi/education/8449307.stm. 
Roberts, Lizzie. "University politics seminars are a breeding ground for chauvinism." The Guardian, 27 March 2015, available at https://www.theguardian.com/education/2015/mar/27/university-politics-seminars-are-abreeding-ground-for-chauvinism.

Rudner, Martin. "Intelligence Studies in Higher Education: Capacity-Building to Meet Societal Demand." International Journal of Intelligence and CounterIntelligence 22, no. 1 (2009): 110-130.

Salmon, Gilly. E-Moderating: The Key to Teaching and Learning Online. $3^{\text {rd }}$ edn. London: Routledge, 2011.

Scott, Len and Peter Jackson. "The Study of Intelligence in Theory and Practice." Intelligence and National Security 19, no. 2 (2004): 139-169.

Sheptycki, James. "Organisational Pathologies in Police Intelligence Systems: Some Contributions to the Lexicon of Intelligence-Led Policing." European Journal of Criminology 1, no. 3 (2004): 307-332.

Swenson, Russell G. "Meeting the Intelligence Community's Continuing Need for an Intelligence Literature.” Defense Intelligence Journal 11, no. 2 (2002): 87-96.

Treverton, Gregory F. Covert Action: The Limits of Intervention in the Postwar World. New York: Basic Books, 1987.

U.S. Department of Defense Office of Inspector General. Unclassified Report of Investigation of Allegations Relating to US CENTCOM Intelligence Products. Washington, DC: DoD Office of Inspector General, 2017.

Wark, Wesley. "Introduction: The Study of Espionage: Past, Present, Future?” Intelligence and National Security 8 no.3 (1993): 1-13.

Wirtz, James J. "The American Approach to Intelligence Studies.” In Loch K. Johnson (ed.), Handbook of Intelligence Studies. Abingdon: Routledge, 2007: 28-38.

Wirtz, James J. "The Art of the Intelligence Autopsy.” Intelligence and National Security 29, no. 1: 1-18.

Woo, Younghee and Thomas C. Reeves."Meaningful Interaction in Web-Based Learning: A social Constructivist Interpretation." Internet and Higher Education 10 (2007): 15-25.

Zegart, Amy. "9/11 and the FBI: The Organisational Roots of Failure." Intelligence and National Security 22, no. 2 (2007):165-184. 